\title{
Cartografia do Invisível: Revelando a Agricultura de Pequena Escala com Imagens Rapideye na Região do Baixo Tocantins, Pa.
}

\section{Cartography of the Invisible: Revealing Small-scale Agriculture by RapidEye Imagery in the Region of Lower Tocantins, PA.}

\author{
Anielli Rosane de Souza* ${ }^{*}($ (D), Maria Isabel Sobral Escada $\square$ (D), \\ Rennan de Freitas Bezerra Marujo $\varangle$ (iD, Antônio Miguel Vieira Monteiro $₫$ (iD) \\ ${ }^{1}$ Instituto Nacional de Pesquisas Espaciais, OBT- São José dos Campos, São Paulo, Brasil. \\ E-mails: isabel.escada@inpe.br (MISE); rennan.marujo@inpe.br (RFBM); \\ miguel.monteiro@inpe.br (AMVM). \\ *E-mail para correspondência: aniellirosane@yahoo.com.br (ARS)
}

Recebido (Received): 07/11/2018 Aceito (Accepted):10/07/2019

\begin{abstract}
Resumo: Dados derivados de sensoriamento remoto aliados ao uso de técnicas de classificação digital de imagens fornecem uma visão sinóptica e informações sobre a dimensão temporal dos fenômenos espaciais, possibilitando gerar informações sobre a dinâmica e os padrões espaciais da paisagem em áreas de grandes extensões territoriais como a Amazônia. Nos mapeamentos extensivos, como os realizados com imagens de satélite pelo INPE para a Amazônia Legal, é comum a definição e descrição de classes de uso e cobertura da terra em função da resolução espacial e radiométrica dos sensores utilizados. Por essa razão, pequenas áreas que não atingem o tamanho mínimo da área de mapeamento e/ou com usos diversificados são, em geral, agregadas em uma única classe. Esse é o exemplo da classe denominada Mosaico de Ocupação presente na legenda do sistema de monitoramento do uso e cobertura da terra da Amazônia-TerraClass. Esta classe procura representar, em parte, a agricultura familiar, no entanto, como o mapeamento é feito pelo sensor TM ou OLI dos satélites da série Landsat, com resolução espacial de $30 \mathrm{~m}$ e como o TerraClass define uma área mínima de mapeamento de 6,25 hectares (ha), a identificação de pequenas áreas agrícolas é comprometida, pois essas categorias são agregadas em classes mistas e não são mais distinguíveis. Para estudos que procuram dar visibilidade aos padrões espaciais de atividades de produção de pequena escala torna-se necessário realizar o refinamento dessas classes com dados de resolução espacial com melhor definição. Neste contexto, o objetivo desse trabalho é testar três algoritmos semiautomáticos de classificação, baseados em pixel e em regiões: os algoritmos MAXVER, Bhattacharya e K-Vizinho Mais Próximo (KNN), para avaliar a capacidade de refinamento da classe Mosaico de Ocupação do dado produzido pelo TerraClass2014. A área de estudo compreende parte dos municípios de Cametá, Mocajuba e Baião, localizados na região Nordeste do Pará, onde a produção de mandioca, pimenta-do-reino, cacau e açaí têm grande importância econômica para população local. Para o mapeamento das categorias contidas na classe Mosaico de Ocupação, foram utilizadas imagens do RapidEye, sensor REIS, ortoimagens com $5 \mathrm{~m}$ de resolução espacial. Foi estimada a exatidão global dos algoritmos testados obtendo-se índices de $26 \%, 38 \%$ e $78 \%$, para os algoritmos MAXVER, Bhattacharya e K-Vizinho Mais Próximo, respectivamente. Além da maior exatidão Global (78\%), o algoritmo K-Vizinho Mais Próximo apresentou melhores resultados relativo às classes de vegetação secundária, hidrografia, e pasto sujo, com mais de $90 \%$ de acerto. A classe agricultura anual de pequena escala apresentou acerto de $62 \%$, enquanto o índice de acerto dos outros dois algoritmos testados não passou de $8 \%$. A abordagem metodológica desenvolvida demonstrou a viabilidade do uso das imagens de alta resolução espacial e de métodos semiautomáticos para a classificação de classes de uso e cobertura da terra associadas à classe Mosaico de Ocupação do TerraClass. A metodologia pode ser utilizada para complementar às atuais bases de dados existentes para a Amazônia (TerraClass, MapBiomas e IBGE), explicitando as categorias agrícolas de produção em pequena escala, dando visibilidade a esses sistemas de produção, frequentemente negligenciados nos mapeamentos que abrangem grandes extensões territoriais.
\end{abstract}


Palavras-chave: Uso e cobertura da terra, paisagem, classificação semiautomática, imagens de alta resolução espacial, RapidEye.

Abstract: Remote sensing-derived data combined with the use of digital classification techniques provides a synoptic view and information about the temporal dimension of the studied phenomena on the territory, making possible to generate information about the landscape dynamic and spatial pattern in regions of large territorial extensions such as Amazon. In the mapping of large areas, such as those performed by INPE for the Legal Amazon with satellite images, land use and land cover classes are in general defined as a function of the spatial and radiometric resolution of the sensors used, so that small areas with diversified uses are generally aggregated into single and mixed class. This is the example of the so-called Mosaic of Uses class of the Land Use and Land Cover Monitoring System of the Amazon-TerraClass. This class represents in part, household agriculture, however, as this mapping is carried out based on TM or OLI images from Landsat series satellites, due to its spatial resolution of $30 \mathrm{~m}$ and the minimum mapping area of 6.25 hectares (ha) defined by TerraClass, the identification of small production scale is compromised, since they are aggregated with other land use and land cover areas no longer distinguishable. For studies that seek to give visibility to small-scale economy spatial patterns, it is necessary to refine these classes with resolution data of better definition. In this context, the main objective of this work is to test three semi-automatic classification algorithms based on pixel and regions were tested, such as MAXVER, Bhattacharya and knearest neighbor $(K N N)$ to evaluate theirs refinement capacity of the Mosaic of Uses class of the data produced by TerraClass-2014. The study area comprises part of the municipalities of Cametá, Mocajuba, and Baião, located in the northeastern region of Pará, where the production of cassava, black pepper, cacao, and açai are economically important for the local population. For the mapping of the categories contained in the Occupancy Mosaic class, images of RapidEye, REIS sensors, orthoimage with $5 \mathrm{~m}$ spatial resolution were used. The accuracy of the tested algorithms were estimated in 26\%, 38\% and 78\% for MAXVER, Bhattacharya and k-nearest neighbor algorithms, respectively. In addition to the greater Global accuracy (78\%), the k-nearest neighbor algorithm presented better results in relation to secondary vegetation, hydrography, and dirty pasture classes, with more than $90 \%$ of accuracy. The small-scale agriculture class presented $62 \%$ of accuracy, while the other two algorithms tested did not exceed $8 \%$. The methodological approach developed demonstrated the feasibility of using spatial high-resolution images and semi-automatic methods to distinguish land use and land cover classes present into TerraClass's Mosaic of Uses class. The methodology can be used to complement the existing databases for the Amazon (TerraClass, MapBiomas, and IBGE), emphasizing small-scale agricultural categories, giving visibility to their production systems, frequently neglected in large extent mappings.

Keywords: Land Use and Land Cover, Landscape, Semi-Automatic Classification, High Spatial Resolution Images, RapidEye.

\section{Introdução}

A Amazônia Legal é palco de diferentes dinâmicas territoriais, resultantes da organização territorial, dos processos histórico-geográficos de ocupação e das atividades desenvolvidas pelos agentes produtores do espaço, que se diferenciam pelas atividades de uso da terra que desenvolvem, imprimindo múltiplos padrões espaciais na paisagem (ESCADA, 2003; SOUZA, 2016). Os padrões espaciais da paisagem podem ser observados com dados derivados de sensoriamento remoto e mapeados a partir de diferentes técnicas de classificação de imagens e da análise da estrutura espacial dos elementos que compõe a paisagem (SILVA; 2008; GAVLAK; 2011; SOUZA 2016).

$\mathrm{O}$ avanço no desenvolvimento de técnicas de classificação digital de imagens, bem como a melhoria na resolução espacial dos sensores tem sido fundamental para o monitoramento do uso e cobertura da terra na Amazônia. Desde a década de 70 é realizado o monitoramento da floresta amazônica, embora os dados tenham sido divulgados de forma anual somente a partir de 1988 pelo Projeto e Monitoramento do Desmatamento Amazônia Legal por Satélite - PRODES (VALERIANO et al., 2012). Diferentemente do PRODES, o Projeto TerraClass tem como objetivo mapear os usos e coberturas da terra das áreas desmatadas da Amazônia Legal identificadas pelo PRODES. Os dados são disponibilizados bianualmente e atualmente estão disponíveis para os anos de 2004, 2008, 2010, 2012 e 2014 (COUTINHO et al., 2013). No mapeamento realizado pelo TerraClass são utilizadas imagens de satélite da série Landsat, CBERS e de séries temporais do MODIS, este último utilizado na classificação da agricultura anual de larga escala (ALMEIDA et al., 2016). A escolha dessa categoria de sensores é devido à sua resolução espacial e à área de abrangência de sua cobertura. A área mínima mapeada pelo TerraClass corresponde a 6,25 hectares 
(VALERIANO et. al., 2012; ALMEIDA et al., 2016).

O TerraClass opera com 12 classes, sendo elas: Agricultura anual; Pasto Limpo, Pasto Sujo, Regeneração com Pasto, Pasto com Solo exposto; Vegetação Secundária, Mosaico de Ocupação, Desflorestamento, Área Urbana, Mineração, Outros e Área Não Observada (COUTINHO et al., 2013). A classe Mosaico de Ocupação é o foco principal desse trabalho. Essa classe incorpora pequenos e diferentes polígonos de usos e cobertura da terra, dentre eles, os relacionados com a agricultura anual familiar e criação de pequenos rebanhos bovinos. As classes de uso e cobertura da terra relativas a esses sistemas produtivos não são discriminadas pelo TerraClass, devido a área mínima definida de mapeamento de 6,25 ha e à resolução espacial dos sensores utilizados (COUTINHO et al., 2013; ALMEIDA et al., 2016). De acordo com o trabalho de Souza et al. (2017), realizado na região sudoeste do Pará, as áreas mapeadas como Mosaico de Ocupação correspondem em grande parte às atividades desenvolvidas pela agricultura $e$ pecuária de pequena escala. Porém, neste estudo, observou-se que muitas das manchas contidas nos polígonos da classe Mosaico de Ocupação não correspondiam a essas classes. Foram observadas com frequência manchas das classes área urbana (associada às comunidades) e vegetação secundária nesses aglomerados.

Na Amazônia, o sistema de produção em pequena escala, geralmente utiliza áreas de tamanho inferior a 1 ha (DAL'ASTA et al., 2014), como é o caso do cultivo da mandioca nas regiões ribeirinhas do Sudoeste do Pará, cujas lavouras compreendem, em geral, áreas de 0,25 ha e não são mapeadas pelo TerraClass. Também as áreas onde ocorrem atividades extrativistas e agroflorestais, o mapeamento não é feito, pois estas áreas estão incluídas ou em áreas de floresta (açaí) e/ou áreas de vegetação secundária (açaí e cacau), difíceis de serem discriminadas apenas com dados provenientes de sensoriamento remoto. Essas áreas não estão explícitas, não apenas no TerraClass, mas também em outros mapas gerados pelos sistemas de monitoramento do uso e cobertura da terra da Amazônia. No TerraClass essas categorias são agrupadas nos polígonos da classe Mosaico de Ocupação, no MapBiomas, esta categoria compõe as classes Agricultura e/ou Agropecuária e, nos mapas de uso e cobertura da terra do IBGE, essas áreas estão incluídas nas classes: Mosaico de Área Agrícola com Remanescentes Florestais e Mosaico de Vegetação Florestal com Atividade Agrícola. Como é possível observar, as classes de uso da terra relativas aos sistemas de pequena escala, sejam eles, agrícolas, pastoris ou agroflorestais, são representadas quase sempre por aglomerados de diversas classes de usos e coberturas da terra (ALMEIDA et al., 2016; IBGE, 2017; PROJETO MAPBIOMAS, 2018).

Em parte, a ausência da classe agricultura de pequena escala, ocorre devido às limitações dos sensores utilizados para o mapeamento em escalas locais e aos aspectos operacionais, pois é necessário, muitas vezes, o uso de um grande conjunto de imagens de resolução espacial com melhor definição para recobrir uma determinada área. Também o tempo de revisita é maior, o que implica na dificuldade em se encontrar imagens livres de cobertura de nuvens. Para uma melhor compreensão e mapeamento das atividades econômicas, relacionadas aos sistemas de produção local de pequena escala, a partir da sua expressão na paisagem, é necessário desenvolver uma proposta metodológica distinta que envolva a deteç̧ão das coberturas associadas a estes sistemas considerando também suas características espaciais. É desejável que os métodos utilizados sejam operacionais, podendo ser automáticos ou semiautomáticos, e que as imagens utilizadas sejam acessíveis, como são as imagens do RapidEye, adquiridas no site do geocatálogo do Ministério do Meio Ambiente (MMA). Porém, as restrições não são apenas operacionais, parte delas se deve ao desinteresse por essas categorias por parte dos tomadores de decisão, refletido nas políticas econômicas que não incluem em seus estudos os arranjos espaciais e produtivos gerados pelas categorias de menores escala e menos capitalizadas. Entretanto, são essas as categorias que abastecem as cidades com alimentos, suprindo grande parte das necessidades nutricionais da população, seja pela comercialização dos produtos nas cidades e arredores, seja pelo autoconsumo (MELLO et al., 2009; COSTA, 2019). Assim, discriminar a agricultura anual de pequena escala é de grande relevância, pois esta classe representa uma das mais importantes bases da economia regional da Amazônia.

$\mathrm{O}$ uso de dados de sensoriamento remoto em conjunto com técnicas de processamento digital de imagens tem se mostrado eficaz para detecção dos processos e dinâmicas de uso e cobertura da terra, incluindo a agricultura, que apresenta grandes variações espectrais, espaciais e temporais. As técnicas de classificação de imagens oferecem algoritmos e métodos que, quando aplicados adequadamente, podem contribuir para a detecção de áreas agrícolas de pequena escala. Dado fundamental para essa detecção são as imagens de alta resolução espacial, como as imagens do REIS/RapidEye-2 (5 metros de resolução espacial) (DURO et al.,2011; SCHUSTER et al.,2012; MORARIU; BURESCU, 2018). Souza et al. (2017), combinou técnicas de classificação manual, interpretação visual e imagens do REIS/RapidEye-2 para classificar agricultura anual de pequena escala na região do Sudoeste do Pará. No entanto, os métodos manuais utilizados têm um custo 
alto em termos de tempo e esforço, sendo pouco operacional para mapeamento de áreas extensas. Diante disso, procurando avançar no que foi desenvolvido por Souza et al. (2017), este trabalho teve por objetivo desenvolver uma matriz metodológica de classificação semiautomática de agricultura anual de pequena escala associada à classe Mosaico de Ocupação, presente no TerraClass do ano de 2014, para a região do baixo Tocantins, na porção nordeste do Pará. Foram testadas técnicas de classificação semiautomáticas em imagens do REIS/RapidEye-2 a partir do uso de três diferentes algoritmos de classificação, um baseado em pixel e os outros dois baseado em regiões: Máxima Verossimilhança (MAXVER), que opera a partir do valor espectral individual do pixel; o classificador Bhattacharya, que se baseia no valor espectral de um conjunto de pixels, agrupados em regiões estabelecidas por um algoritmo de segmentação, de crescimento por regiões e classificado com base na distância de Bhattacharya e; $o$ algoritmo de classificação por $K$-Vizinho Mais Próximo $(K N N)$, que opera a partir do agrupamento de pixels obtidos com um algoritmo de segmentação multiresolução e com o uso de atributos espectrais e espaciais para determinar a classe na qual um conjunto de pixels (regiões) deve pertencer. Esses classificadores têm sido tradicionalmente utilizados para mapear o uso e cobertura da terra e maiores detalhes sobre eles podem ser obtidos em Mather (1993), Gonzalez e Woods (2000) e Richards e Jia (2005).

\section{1.Área de Estudo}

Á área de estudo compreende uma cena REIS/RapidEye-2, identificada pelo número 2337821, localizada na região do Baixo Tocantins, e envolve parte dos municípios de Mocajuba, Cametá e Baião no Pará (Figura 1). A região do Baixo Tocantins tem um histórico de ocupação que se intensifica por volta do século XVII, e atualmente apresenta diferentes usos e coberturas da terra, influenciados por distintos processos de ocupação e diferentes dinâmicas econômicas. Nessa área estão localizadas populações que apresentam formas de ocupação distintas, podendo ser destacadas: a população ribeirinha, presente na região desde a colonização do século XVII, que teve que se adaptar aos regimes sazonais do rio Tocantins, cujas atividades de uso da terra mais frequentes são as tradicionais como o extrativismo, principalmente do açaí e pesca, complementada pela agricultura de pequena escala como a produção de arroz, mandioca, milho e feijão destinados à manutenção familiar. A população de terra firme representa as formas de colonização mais recentes da região, cujas atividades estão baseadas principalmente na silvicultura ou na agricultura, como a produção de açaí de terra firme mecanizado e irrigado, muitas vezes consorciado com pimenta-do-reino, cacau e também com a piscicultura. Essas atividades são favorecidas pelo relevo mais plano e pela pouca influência da sazonalidade das águas. A pecuária, diferentemente de grande parte dos municípios da Amazônia, é uma atividade pouco praticada. O dado do IBGE de Produção da Pecuária Municipal (PPM), mostra que, em 2015, por exemplo, Cametá contava com apenas 501 cabeças de gado e Mocajuba com 1.752 cabeças. Apenas Baião apresentou valores significativos dessa atividade, contando com 64.870 cabeças, um número superior aos dos outros dois municípios (LIMA et al., 2001; BASTOS et al., 2010; IBGE, 2015). A Tabela 1 apresenta a área plantada nos municípios que envolvem a região de estudo em 2014. Nota-se que as culturas relacionadas com a alimentação básica e tradicional brasileira (arroz e feijão) estão presentes, mas não ocupam áreas extensas, sendo a mandioca o produto de consumo local mais relevante, um indicativo da importância da produção familiar de pequena escala na região.

Tabela 1: Uso da terra na região de estudo.

\begin{tabular}{lccc}
\hline Uso da terra em 2014 & \multicolumn{4}{c}{ Área Plantada ha. } \\
\hline Lavoura permanente & Mocajuba & Cametá & Baião \\
Cacau & 1.125 & 6.396 & 250 \\
Pimenta-do-reino & 469 & 440 & 1.250 \\
Lavoura temporária & & & \\
Arroz & 50 & 250 & 50 \\
Feijão & 0 & 180 & 0 \\
Mandioca & 700 & 7.000 & 300 \\
Milho & 50 & 150 & 150 \\
Efetivo rebanho & \multicolumn{4}{c}{ Número de cabeças } \\
Bovino & 1.752 & 501 & 64.870 \\
Área territorial $\left(\mathrm{Km}^{2}\right)$ & 871,171 & $3.081,367$ & $3.759,834$ \\
\hline
\end{tabular}

Fonte: IBGE (2015)

Na cena escolhida do REIS/RapidEye-2 estão contidos 5.952 ha de área da classe Mosaico de Ocupação mapeados em 2014 (ALMEIDA et al., 2016). A Figura 1 apresenta a localização da área de estudo e as áreas de Mosaico de Ocupação. 


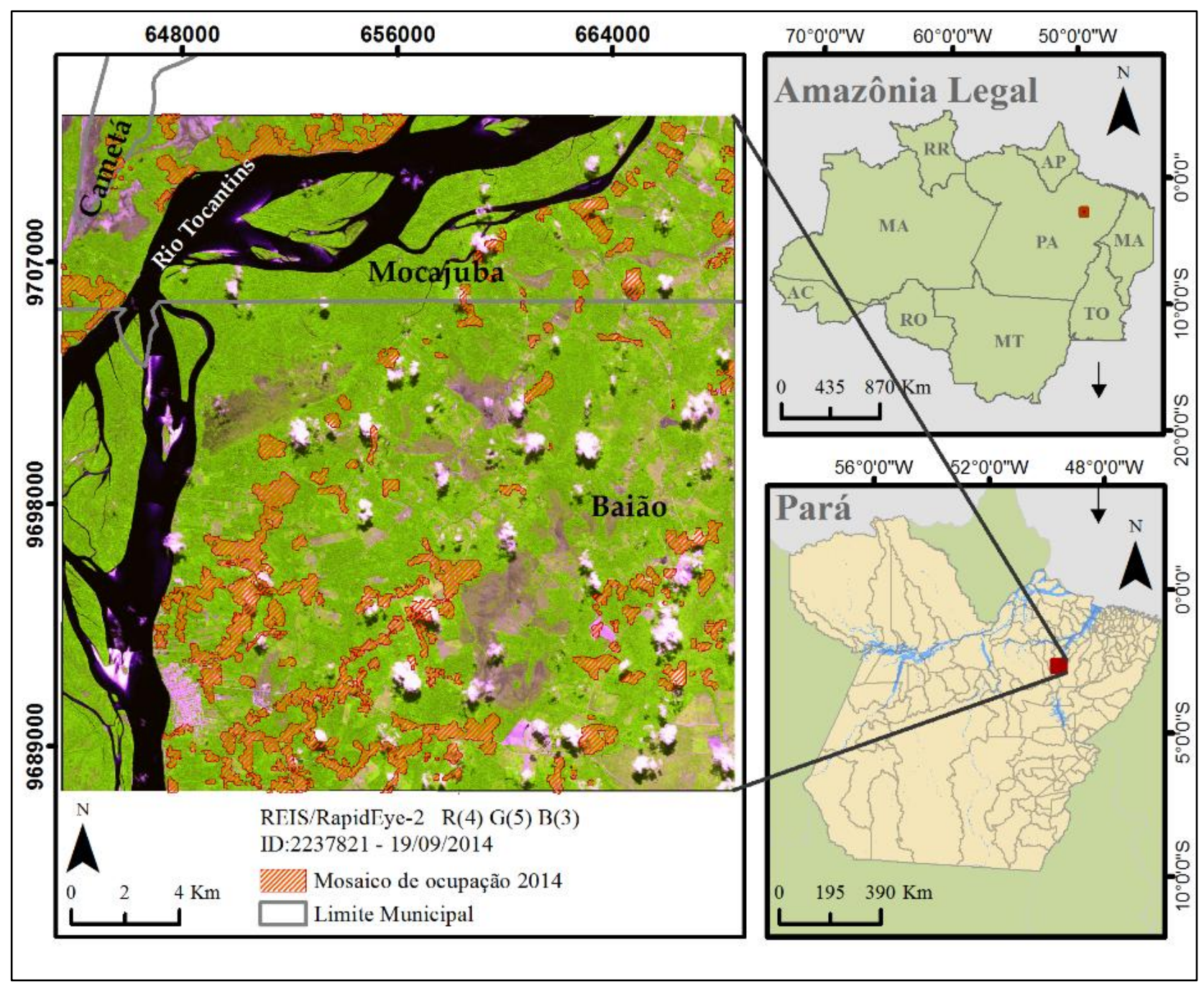

Figura 1: Localização da cena 2337821 do REIS/RapidEye-2 nos municípios de Cametá, Mocajuba e Baião.

\section{Materiais e Métodos}

As metodologias testadas para classificação da agricultura anual de pequena escala contidas dentro do polígono Mosaico de Ocupação foram desenvolvidas por meio de três diferentes procedimentos. A Figura 2 apresenta o fluxograma com as principais etapas metodológicas seguidas.

Os procedimentos para a classificação foram divididos em três etapas: 1) Pré-processamento; 2) Classificação e; 3) Avaliação. Na etapa de pré-processamento, foi realizada a seleção da imagem do REIS/RapidEye-2 (19 de setembro de 2014), adquirida do geocatálogo do Ministério do Meio Ambiente (MMA) e, em seguida, foi realizado o seu corregistro com a imagem OLI/Landsat 8, adquirida em 22 de agosto de 2014 e utilizada na classificação do TerraClass 2014. O objetivo do corregistro foi obter um melhor ajuste entre as feições contidas na imagem do RapidEye e os limites das classes do TerraClass2014. Para isso foi utilizando o software TerraPixel (Versão 1.0.4) (CASTEJON, 2019), no qual está implementado três diferentes métodos de aquisição de pontos de controle: manual, automático e semiautomático. Nesse trabalho, utilizou-se a forma semiautomática para aquisição dos pontos, nesse método o usuário define a área em que os pontos são coletados. Embora as imagens tenham resolução espacial diferentes, OLI/Landsat-8 com 30 metros e RapidEye com 5 metros, é possível identificar em ambas as imagens algumas feições comuns como, por exemplo, o cruzamento de estradas, área urbana e rios, possibilitando utilizar o método de registro semiautomático. Caso não fosse possível identificar essas feições, não seria possível fazer uso dessa técnica, pois poucos alvos resultam em valores baixos de registrabilidade (CHALERMWAT, 1999). Em seguida, a imagem do RapidEye foi ajustada com base no interpolador vizinho mais próximo, obtendo-se, assim, o corregistro da RapidEye com a imagem de referência (OLI/Landsat-8). Após a imagem estar corregistrada, com erro médio estimado, RMS (Root Mean Square), entre 0,5 e 0,7 pixel da imagem de referência (OLI/Landsat-8). 


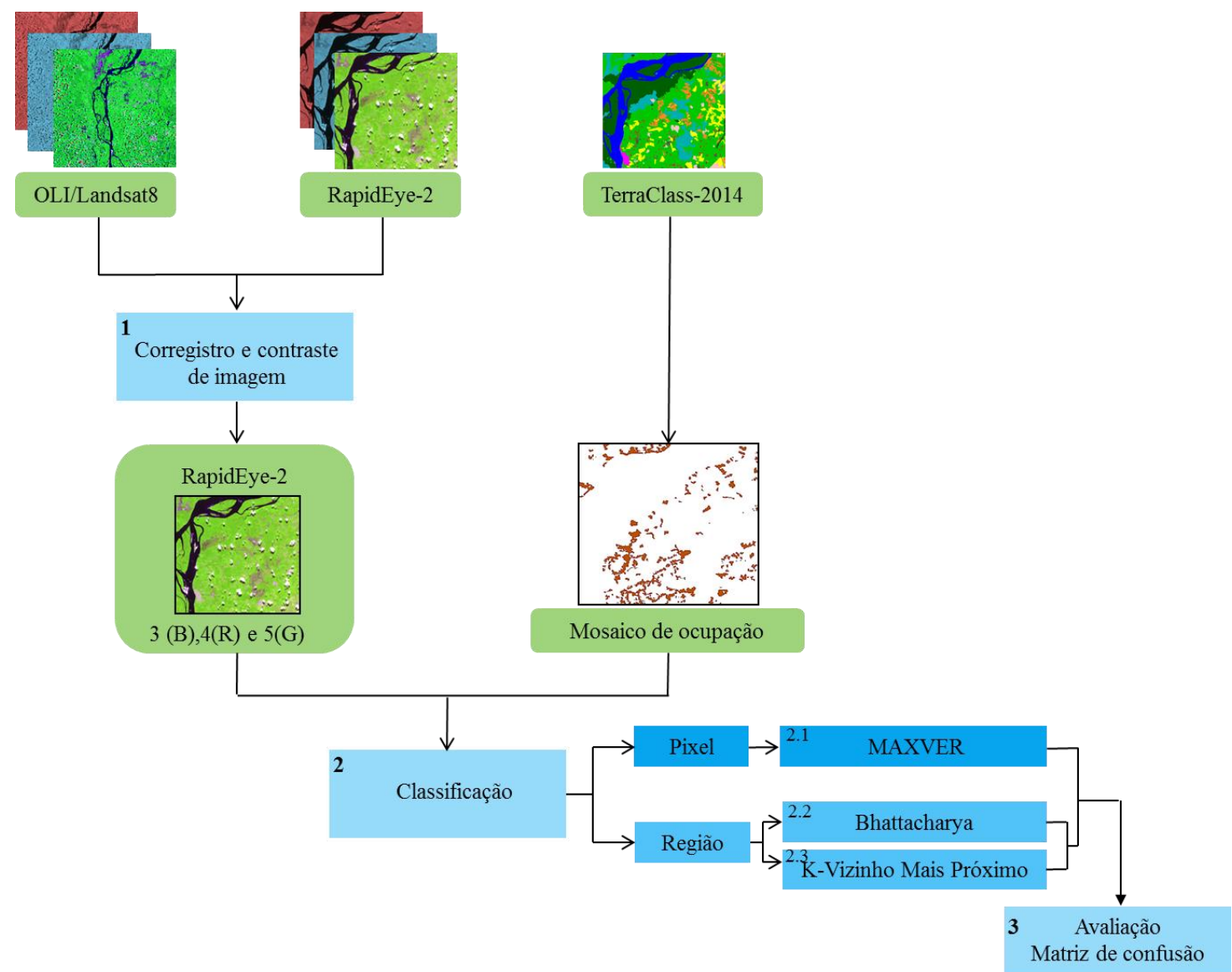

Figura 2: Fluxograma metodológico das principais etapas de classificação baseada nos classificadores MAXVER, Bhattacharya e K-Vizinho Mais Próximo.

Com a imagem registrada, foi aplicado um contraste linear das bandas espectrais, bandas 3 (vermelho: $630-685 \mathrm{~nm}$ ), 4 (vermelho limítrofe: $690-730 \mathrm{~nm}$ ) e 5 (infravermelho próximo: $760-850 \mathrm{~nm}$ ), associadas respectivamente aos canais, B (azul), R (vermelho) e G (verde). A banda 4, conhecida como Red-Edge foi uma das bandas utilizada para o mapeamento da classe agricultura anual de pequena escala. Essa banda é o que distingue o sensor do RapidEye dos outros sensores multiespectrais, por ser uma banda mais sensível à clorofila, e contribui para melhorar o desempenho da classificação do uso e cobertura da terra, sendo utilizada em diferentes trabalhos associados à índice de área foliar, estádio da vegetação e de culturas agrícolas (RAMOELO et al.,2012; SCHUSTER et al., 2012; ANTUNES et al., 2014; USTUNER et al.,2015; BENÍTEZ et al., 2016; PLANET BLACKBRIDGE, 2016). É importante destacar que nem todas as áreas de agricultura anual de pequena escala estão contidas na classe Mosaico de Ocupação, mas este trabalho tem como foco estabelecer procedimentos para o refinamento para esta classe (Mosaico de Ocupação).

As classes utilizadas para refinar Mosaico de Ocupação foram as mesmas definidas no TerraClass (ALMEIDA et al., 2016) entretanto, alguns ajustes foram feitos conforme sugerido por Souza et al. (2017): as classes pasto sujo e regeneração com pasto foram agrupadas em uma única classe, mantendo o nome pasto sujo. Esse ajuste foi realizado porque a classe regeneração com pasto é pouco representativa em termos de área, representando 1 ha em Cametá e 529 ha em Mocajuba. No município de Baião a classe regeneração com pasto apresenta 2.000 ha, mas esse valor não influencia o resultado do mapeamento, visto que a pastagem tem o mesmo peso para análises futuras. Na Tabela 2 é apresentada a descrição das classes presentes na categoria Mosaico de Ocupação e que foram utilizadas no refinamento:

Dando sequência à classificação, na abordagem por pixel adotou-se o classificador supervisionado MAXVER do Sistema de informação geográfica (SIG) SPRING (versão 5.5.1) (CÂMARA et al., 1996). Esse classificador utiliza um modelo paramétrico que se baseia na distribuição normal Gaussiana multivariada para determinar, a partir das amostras, a probabilidade de um pixel pertencer a uma determinada classe (RICHARDS; JIA, 2005). O processo para classificação inicia-se com a coleta de amostras de pixel para cada classe. Na etapa de aquisição das amostras foi levada em conta a distribuição das amostras e o número de pixels coletado para cada classe, que variou de acordo com a área que a classe ocupava dentro do polígono Mosaico de Ocupação. Esta etapa exigiu um considerável esforço amostral, e teve como finalidade minimizar a confusão entre as feições de cada classe e os diversos aspectos em que uma mesma classe se comportava na imagem. 
Tabela 2: Classes utilizadas no refinamento da Classe Mosaico de Ocupação.

\begin{tabular}{ll}
\hline Classe & \multicolumn{1}{c}{ Descrição } \\
\hline Vegetação secundária & Representa áreas de regeneração que sofreram supressão total da cobertura florestal e \\
& foram posteriormente abandonadas. \\
Pasto limpo & Representa áreas nas quais predominam vegetação herbácea e gramínea. Nessa classe \\
& foi incluída a classe pasto com solo exposto, de forma que podem ocorrer algumas \\
& manchas de solo exposto nas áreas de pasto, minoritariamente. \\
Pasto sujo & Área com predomínio de gramíneas, podendo ocorrer vegetação arbustiva esparsa e \\
& poucos indivíduos arbóreos. Nessa classe está inclusa a classe regeneração com \\
& pasto. Assim, nessa classe pode ocorrer em algumas áreas uma vegetação arbustiva \\
& mais densa. \\
Área urbana & Corresponde a áreas de aglomerados populacionais, como cidades, comunidades e \\
Outros & vilas. \\
Hidrografia & Esta classe se constitui em um agregado de usos e cobertura da terra tais como, \\
& afloramentos rochosos, bancos de areia e estradas. \\
Agricultura anual de pequena & Corresponde às áreas que reúnem diferentes tipos de corpos d'água como rios, lagoas, \\
escala & represas e etc. \\
& A classe agricultura anual de pequena escala representa áreas agrícolas de pequena \\
Áreas não observadas & desenvolvida predominantemente com mão de obra familiar. \\
\hline
\end{tabular}

Fonte: Adaptado de Coutinho et al. (2013) e Souza (2016).

A segunda técnica de classificação testada adotou-se a abordagem por região, utilizando o classificador de Mínima Distância Estocástica - Bhattacharya (MATHER, 1993) e o SIG SPRING (versão 5.5.1) (CÂMARA et al., 1996). Este processamento inicia-se com a segmentação para definição de regiões homogêneas, no qual foi adotado o algoritmo de crescimento por regiões, desenvolvido para o SPRING (CÂMARA et al., 1996), em que limiares de similaridade e de área (pixel) são definidos empiricamente. O valor do limiar de similaridade e de tamanho de área adotados foram 8 (oito) e 16, respectivamente. Em seguida, foi realizada a extração de atributos das regiões, neste caso, a média de cada segmento para cada banda, e após esse procedimento foram selecionadas as amostras de treinamento para cada classe. Utilizou-se o classificador (Bhattacharya), que mede a separabilidade estatística entre um par de classes espectrais, que é calculada pela distância média entre as distribuições de probabilidades de classes espectrais, gerando assim, um mapa temático de uso e cobertura da terra.

Na terceira e última abordagem, utilizou-se o software eCognition (versão 8.0), em que foi possível testar o classificador K-Vizinho Mais Próximo, associado aos atributos e ao valor médio dos níveis de cinza de cada banda que também contou com uma etapa de segmentação multiresolução (BAATZ; SCHAPE, 2000). A implementação do algoritmo de segmentação multiresolução de Baatz e Schape (2000), presente no software eCognition, consiste em uma abordagem de segmentação por crescimento de regiões. Nesta abordagem duas regiões vizinhas são analisadas e, dado um critério de similaridade, elas são agrupadas em uma única região, caso esse critério de similaridade seja atendido. Para verificar quão similares são duas regiões, o algoritmo utiliza atributos de cor e forma. Ambos os atributos são analisados como elementos complementares, de modo que ao priorizar um deles, o outro atributo passa a ter menor influência na métrica de similaridade. Os valores dos atributos devem estar entre 0 e 1 e a soma deles deve ser 1 . Por exemplo, ao dar prioridade de 0.8 para o atributo cor, o algoritmo atribui automaticamente o valor 0.2 para forma. $\mathrm{O}$ atributo cor representa as variações nos valores de pixel dentro do segmento para cada banda espectral, definido pela soma ponderada dos desvios-padrão de cada banda. Esse atributo possibilita separar objetos com tonalidades diferentes. Enquanto a forma é constituída por dois atributos, compacidade e suavidade (complementares entre si). A compacidade representa o quão compacto é um objeto, ou seja, o quão próximo do centro do segmento os pixels estão distribuídos. A compacidade é definida matematicamente pela razão entre o perímetro de um objeto e a raiz quadrada do número de pixels do mesmo. A suavidade é uma métrica utilizada para avaliar se um segmento apresenta curvas em sua geometria e se o mesmo é alongado ou não. Essa métrica é expressa pela razão entre o perímetro do objeto e o perímetro do retângulo envolvente, paralelo às suas bordas do objeto analisado. O usuário define um limiar para a escala e o valor dos parâmetros, de modo que os segmentos são criados seguindo estas diretrizes. (BAATZ; SCHAPE, 2000; MOLLAEI; KARAMSHAHI, 20019).

Desta forma, baseados na literatura (RICHARDS; JIA, 2005; MENESES; ALMEIDA, 2012; SCHUSTER et al., 2012; USTUNER et al., 2015), adotaram-se as seguintes bandas e parâmetros: 1) as bandas 3, 4 e 5 foram utilizadas na segmentação por discriminarem melhor os alvos da superfície terrestre; 2 ) 
o valor utilizado da escala foi 60 , determinado empiricamente em função do tamanho dos objetos (agricultura anual de pequena escala, pasto, vegetação secundária e etc.) e da resolução espacial da imagem ( 5 metros), de forma que os segmentos gerados fossem o mais homogêneo possível, reduzindo-se assim, a inclusão de pixel com características distintas das daquele segmento; 3) para forma foi atribuído o valor 0,6, o que implica em 0,4 para cor, pois se observou na imagem que a classe de interesse, as áreas de agricultura anual de pequena escala, tem forma retangular bem definida enquanto o nível de cinza observado na imagem utilizada variou de acordo com o estádio da vegetação e; 4) valor 0,5 para suavidade, o que implica na atribuição do valor 0,5 para compacidade. Esses valores foram definidos empiricamente para que os segmentos resultantes do processo de segmentação adequassem a geometria dos alvos presentes na superfície da Terra, de modo que as bordas dos segmentos evitassem que pixels de diferentes classes, com diferentes valores de nível de cinza nas bandas espectrais consideradas, fossem incluídos em um mesmo segmento. Após a definição dos parâmetros procedeu-se com a segmentação e, posteriormente, com a análise visual dos segmentos (GAMANYA et al.2007), para verificar se eram compostos por pixels de uma única classe. Em seguida, a partir da seleção de amostras de treinamento (segmentos) de cada classe, aplicou-se o classificador K-Vizinho Mais Próximo (KNN) e os parâmetros brilho e média dos valores das bandas 3, 4 e 5; desvio padrão e forma. O classificador $K N N$, classifica um segmento, definido por diversos parâmetros, podendo ou não serem incluídos alguns parâmetros como brilho e média dos valores das bandas 3 , 4 e 5; desvio padrão e forma.

Obtidas as três classificações, na etapa final, os resultados de cada uma delas foram avaliados por meio de uma matriz de confusão, pelo índice de exatidão global, índice Kappa (COHEN, 1960) e pelos erros de omissão e comissão. O coeficiente de concordância Kappa é um índice que avalia o grau de concordância entre classes de dois mapas ou entre um mapa e um conjunto de dados de referência, baseado em amostras dependentes. Entretanto, por ser um índice geral, é útil para uma análise genéricas da classificação, porém, não é suficiente para avaliar a concordância de cada classe, especificamente. Por esta razão, é realizada de forma complementar, a análise das classes diretamente na matriz de confusão e verificada sua concordância com as amostras de referência (COHEN, 1960; HUDSON; RAMM, 1987).

Foi realizada uma amostragem aleatória estratificada por classe, considerando a representatividade das classes, na qual a quantidade de amostra é definida proporcionalmente à área que as mesmas ocupam na região mapeada. A área mapeada de cada classe foi calculada e é apresentada na seção 3. Foram gerados no total 410 pontos de amostra, sendo 80 pontos para a classe vegetação secundária, a mais representativa de todas as classes; 50 pontos para as classes pasto limpo, pasto sujo, outros, área urbana, agricultura anual de pequena escala, área não observada e; 30 pontos para a classe hidrografia. Como não são muitas classes e as quantidades de pontos gerados para cada classe não são muito discrepantes, segundo Stehman (1996), o uso da estatística Kappa é adequado. Para a amostragem, foi utilizada a ferramenta HawthsTools (create random points) (ArcMap, versão 10.2). Esses pontos foram avaliados com as imagens do RapidEye e conferidos, de forma complementar, com imagens de alta resolução espacial utilizando as imagens distribuída pela agência espacial Francesa Centre National d'Études Spatiales- CNES, disponíveis na plataforma Google Earth, do mês de julho de 2014.

Vale ressaltar que as classificações foram realizadas apenas para a classe Mosaico de Ocupação do TerraClass2014 que, como o próprio nome diz, é um mosaico de classes de uso e cobertura da terra que, para os propósitos dessa pesquisa, devem ser desagregadas.

\section{Resultados e Discussão}

Através das três técnicas de classificação foram gerados três mapas de uso e cobertura da terra e suas respectivas matrizes de confusão, exibidos na Figura 3. Complementarmente, na Tabela 3 estão descritas as proporções de cada classe mapeada dentro do polígono Mosaico de Ocupação, considerando as três abordagens.

As matrizes de confusão (Figuras 4, 5 e 6) foram utilizadas para a avaliação do desempenho dos três procedimentos adotados, possibilitando observar os erros de classificação, a exatidão global e o índice Kappa. 


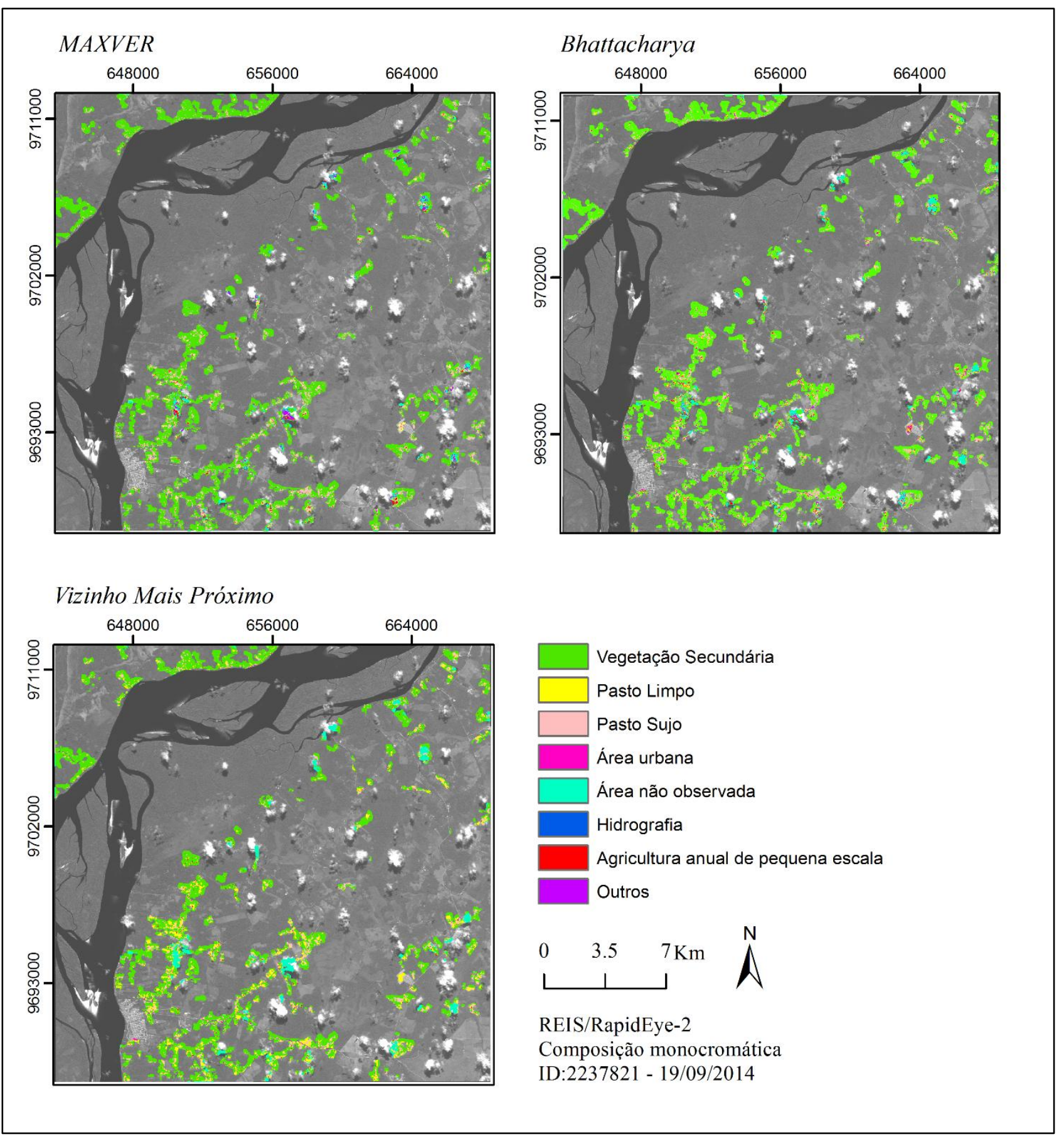

Figura 3: Resultado da Imagem classificadas a partir das três técnicas de classificação com os algoritmos MAXVER, por pixel; Bhattacharya e K-Vizinho mais próximo, por regiões.

Tabela 3: Proporção dos usos e coberturas mapeados em cada abordagem.

\begin{tabular}{lcccccc}
\hline Classes & \multicolumn{2}{c}{ Maxver } & \multicolumn{2}{c}{ Bhattacharya } & \multicolumn{2}{c}{ K-Vizinho Mais Próximo } \\
\cline { 2 - 7 } & Área (Ha) & $\%$ & Área (Ha) & $\%$ & Área (Ha) & $\%$ \\
\cline { 2 - 7 } Vegetação Secundária & 4.575 & 76,85 & 4.334 & 72,82 & 4.069 & 68,36 \\
Pasto Limpo & 188 & 3,16 & 157 & 2,64 & 660 & 11,08 \\
Pasto Sujo & 736 & 12,37 & 797 & 13,38 & 761 & 12,79 \\
Outros & 93 & 1,57 & 127 & 2,13 & 48 & 0,80 \\
Área Urbana & 34 & 0,57 & 41 & 0,69 & 6 & 0,10 \\
Agricultura anual de & 74 & 1,23 & 140 & 2,35 & 56 & 0,95 \\
pequena escala & & & & & & \\
Area Observada & 252 & 4,23 & 355 & 5,97 & 349 & 5,86 \\
Hidrografia & 1 & 0,02 & 1 & 0,02 & 3 & 0,05 \\
\hline
\end{tabular}




\begin{tabular}{|c|c|c|c|c|c|c|c|c|c|c|}
\hline \multicolumn{11}{|c|}{ MAXVER } \\
\hline \multirow{10}{*}{$\begin{array}{l}\frac{\pi}{0} \\
\frac{0}{0} \\
\frac{0}{0} \\
\frac{0}{20}\end{array}$} & $\%$ & \multicolumn{8}{|c|}{ Classificação } & \multirow[b]{2}{*}{$\begin{array}{c}\mathrm{N}^{\mathrm{o}} \text { de } \\
\text { amostras }\end{array}$} \\
\hline & Classes & Vegetação secundária & Pasto Limpo & Pasto sujo & Outros & Área urbana & $\begin{array}{c}\text { Agricultura } \\
\text { anual de } \\
\text { pequena escala }\end{array}$ & $\begin{array}{c}\text { Área não } \\
\text { observada }\end{array}$ & Hidrografia & \\
\hline & Vegetação secundária & 66 & 14 & 16 & 0 & 0 & 3 & 1 & 0 & 80 \\
\hline & Pasto Limpo & 2 & 30 & 26 & 6 & 2 & 2 & 32 & 0 & 50 \\
\hline & \begin{tabular}{|l|} 
Pasto sujo \\
\end{tabular} & 26 & 50 & 22 & 0 & 0 & 2 & 0 & 0 & $\mathbf{5 0}$ \\
\hline & Outros & 0 & 22 & 0 & 8 & 0 & 4 & 66 & 0 & 50 \\
\hline & Área urbana & 6 & 24 & 8 & 4 & 1 & 0 & 57 & 0 & 50 \\
\hline & $\begin{array}{l}\text { Agricultura anual de pequena } \\
\text { escala }\end{array}$ & 10 & 28 & 14 & 6 & 0 & 8 & 32 & 2 & $\mathbf{5 0}$ \\
\hline & Área não observada & 14 & 10 & 4 & 16 & 16 & 10 & 30 & 0 & 50 \\
\hline & Hidrografia & 0 & 0 & 0 & 0 & 0 & 0 & 97 & 3 & 30 \\
\hline
\end{tabular}

Figura 4: Matriz de confusão do Classificador MAXVER.

\begin{tabular}{|c|c|c|c|c|c|c|c|c|c|c|}
\hline \multicolumn{11}{|c|}{ Bhattacharya } \\
\hline \multirow{10}{*}{$\begin{array}{l}\frac{\pi}{0} \\
\frac{0}{0} \\
\frac{0}{0} \\
\frac{0}{2}\end{array}$} & $\%$ & \multicolumn{8}{|c|}{ Classificação } & \multirow[b]{2}{*}{$\begin{array}{c}\mathrm{N}^{\circ} \text { de } \\
\text { amostras }\end{array}$} \\
\hline & Classes & Vegetação secundária & Pasto Limpo & Pasto sujo & Outros & Área urbana & $\begin{array}{c}\text { Agricultura } \\
\text { anual de } \\
\text { pequena escala }\end{array}$ & $\begin{array}{c}\text { Área não } \\
\text { observada }\end{array}$ & Hidrografia & \\
\hline & Vegetação secundária & 69 & 10 & 16 & 0 & 0 & 0 & 5 & 0 & 80 \\
\hline & Pasto Limpo & 0 & 58 & 22 & 4 & 0 & 8 & 8 & 0 & 50 \\
\hline & \begin{tabular}{|l|} 
Pasto sujo \\
\end{tabular} & 28 & 28 & 36 & 2 & 0 & 4 & 2 & 0 & 50 \\
\hline & Outros & 2 & 34 & 16 & 10 & 0 & 4 & 34 & 0 & 50 \\
\hline & Área urbana & 0 & 54 & 0 & 2 & 12 & 4 & 28 & 0 & 50 \\
\hline & $\begin{array}{l}\text { Agricultura anual de pequena } \\
\text { escala }\end{array}$ & 20 & 38 & 16 & 0 & 0 & 4 & 22 & 0 & 50 \\
\hline & Área não observada & 4 & 16 & 0 & 0 & 0 & 2 & 76 & 2 & 50 \\
\hline & Hidrografia & 0 & 0 & 0 & 0 & 0 & 0 & 83 & 17 & 30 \\
\hline
\end{tabular}

Figura 5: Matriz de confusão do Classificador Bhattacharya.

\begin{tabular}{|c|c|c|c|c|c|c|c|c|c|c|}
\hline \multicolumn{11}{|c|}{ K-Vizinho Mais Próximo } \\
\hline \multirow{10}{*}{ 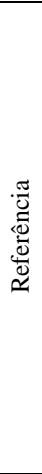 } & $\%$ & & & & Classifi & & & & & \\
\hline & Classes & Vegetação secundária & Pasto Limpo & $\begin{array}{l}\text { Pasto } \\
\text { sujo }\end{array}$ & Outros & $\begin{array}{l}\text { Área } \\
\text { urbana }\end{array}$ & $\begin{array}{l}\text { Agricultura } \\
\text { anual de } \\
\text { pequena escala }\end{array}$ & $\begin{array}{c}\text { Área não } \\
\text { observada }\end{array}$ & $\begin{array}{c}\text { Hidrografi } \\
\mathrm{a}\end{array}$ & $\begin{array}{l}\mathrm{N}^{\circ} \text { de } \\
\text { amostras }\end{array}$ \\
\hline & Vegetação secundária & 99 & 0 & 1 & 0 & 0 & 0 & 0 & 0 & 80 \\
\hline & Pasto Limpo & 6 & 72 & 16 & 4 & 0 & 0 & 2 & 0 & 50 \\
\hline & Pasto sujo & 6 & 0 & 94 & 0 & 0 & 0 & 0 & 0 & 50 \\
\hline & \begin{tabular}{|l|} 
Outros \\
\end{tabular} & 0 & 0 & 7 & 40 & 0 & 0 & 53 & 0 & 50 \\
\hline & Área urbana & 0 & 10 & 0 & 30 & 20 & 0 & 40 & 0 & 50 \\
\hline & $\begin{array}{l}\text { Agricultura anual de pequena } \\
\text { escala }\end{array}$ & 4 & 0 & 12 & 18 & 0 & 62 & 4 & 0 & 50 \\
\hline & Área não observada & 4 & 0 & 0 & 0 & 0 & 0 & 96 & 0 & 50 \\
\hline & Hidrografia & 0 & 0 & 0 & 0 & 0 & 0 & 1 & 99 & 30 \\
\hline
\end{tabular}

Figura 6: Matriz de confusão do Classificador K-Vizinho Mais Próximo.

Na classificação derivada da técnica MAXVER (Figura 4), observa-se o baixo desempenho do algoritmo em discriminar algumas classes como, por exemplo pasto limpo (30\% de acerto) que foi confundido com as classes área não observada (32\%), pasto sujo (26\%), outros (6\%), vegetação secundária (2\%), área urbana (2\%) e agricultura anual de pequena escala (2\%). É comum a classe pasto limpo ser confundida com a classe pasto sujo, pela similaridade entre essas classes e pela dificuldade em se estabelecer um limiar de separação, até mesmo visualmente, entre as duas categorias. Em relação a classe pasto sujo (com $22 \%$ de acerto) houve confusão com as seguintes classes: pasto limpo (50\%), vegetação secundária (26\%) e agricultura anual de pequena escala (2\%). A confusão com a classe pasto limpo já foi mencionada e com a classe vegetação secundária, ocorre principalmente nas áreas que apresentam estágio inicial de regeneração, cujo processo se dá, em grande parte, pelo abandono de áreas de pastagem, e pela invasão de espécies arbustivas e arbóreas que, em estágios iniciais, apresentam características de pasto sujo. A classe outros (8\% de acerto), teve baixa acurácia, sendo confundida com classes com níveis de cinzas distintos, como área não observada (66\%), pasto limpo (22\%) e agricultura anual de pequena escala (4\%). A classe área urbana foi a que apresentou acurácia mais baixa, com apenas $1 \%$ de acerto. Essa imprecisão na classe área urbana ocorre porque ela representa áreas muito pequenas, quase sempre abaixo da área mínima de mapeamento que, de acordo com o teorema de Nyquist-Shannon (Shannon, 1998), é de duas vezes a resolução espacial do sensor nas duas dimensões, ou seja, 2 X 2 pixels ou 60 X $60 \mathrm{~m}$. As confusões dessa classe se deram com 
área não observada (57\%), pasto limpo (24\%), pasto sujo (8\%) e outros (4\%). A classe de interesse, agricultura anual de pequena escala (8\%) também apresentou baixa acurácia, confundindo com as classes área não observada (32\%), pasto limpo (28\%), pasto sujo (14\%), vegetação secundária (10\%), outros (6\%) e hidrografia (2\%). A classe área não observada (30\%), confundiu com as classes, área urbana (16\%), outros (16\%), vegetação secundária (16\%), pasto limpo (10\%) e pasto sujo (4\%), enquanto a classe hidrografia (3\%), confundiu com a classe área não observada (97\%), devido a presença de sombra de nuvens na classe área não observada, onde a tonalidade desses alvos é muito próxima. A classe vegetação secundária foi a que apresentou melhor acurácia (66\%) dentre as demais, no entanto, houve confusão com pasto sujo (16\%), pasto limpo (14\%), agricultura anual de pequena escala (3\%) e área não observada (1\%). Essa baixa acurácia das classes resultou em 26\% de exatidão global e um índice Kappa baixo, de 0,10.

Diferentemente da abordagem anterior, na abordagem por regiões, que utiliza a distância de Bhattacharya, (Figura 5) apresentou maior acurácia para as classes vegetação secundária (69\%), pasto limpo (58\%) e área não observada (76\%), enquanto as demais classes tiveram melhoria menos significativas nos índices de acerto. A classe pasto limpo (58\%) ainda apresentou confusão maior com pasto sujo (22\%), e a classe pasto sujo (36\%) teve maior confusão com as classes pasto limpo (28\%) e vegetação secundária (28\%). A classe outros (10\%), confundiu com classes bem distintas em relação ao nível de cinza tais como, pasto limpo (34\%), área não observada (34\%), pasto sujo (16\%). As classes área urbana, agricultura anual de pequena escala e hidrografia apresentaram uma alta incerteza, de $12 \%, 4 \%$ e $17 \%$, respectivamente. Cabe destacar que a agricultura anual de pequena escala apresentou confusão com as classes, pasto limpo (38\%), área não observada (22\%), vegetação secundária (20\%) e pasto sujo (16\%), mostrando que esse algoritmo não é o mais adequado para o mapeamento dessas áreas. A melhor acurácia estimada em grande parte das classes, influenciou os índices gerais. A medida de exatidão global atingiu 38\% e o índice Kappa 0,26, ainda muito baixo. A melhoria nos índices pode estar relacionada com a segmentação por regiões, que passa por uma etapa em que é feita a extração de atributos, na qual a distância média entre distribuições de probabilidade de níveis de cinza de cada segmento é calculada para cada banda, favorecendo uma melhor distinção entre as classes. Embora os índices de acurácia da classificação derivada do classificador Bhattacharya, tenham sido mais altos do que os apresentados com o MAXVER, em geral, o resultado também não é satisfatório, pois as classes tiveram alto índice de confusão.

Finalmente, a técnica baseada no classificador $K N N$ e segmentação multi-resolução, que considera além dos atributos espectrais, atributos de forma, apresentou maior consistência. A Figura 6 mostra que metade das classes apresentaram acerto superior a 90\%, tais como, vegetação secundária (99\%) que confundiu apenas com pasto sujo (1\%); a classe hidrografia (99\%) que confundiu com a classe área não observada (1\%); a área não observada (96\%) que confundiu com a classe vegetação secundária (4\%) e; a classe pasto sujo (94\%) que apresentou confusão com vegetação secundária (6\%). A outra metade das classes obtiveram acerto inferior a $75 \%$ tal como, pasto limpo (72\%) que confundiu com as classes, pasto sujo (16\%), vegetação secundária (6\%) e outros (4\%). A classe outros (40\%) apresentou confusão com as classes área não observada (53\%) e pasto sujo (7\%) enquanto a classe área urbana (20\%) apresentou confusão com as classes área não observada (40\%), outros (30\%) e pasto limpo (10\%). Como discutido anteriormente, a classe área urbana embora tenha apresentado uma melhoria em sua detecção quando comparada com o resultado dos outros dois algoritmos utilizados, apresenta áreas muito pequenas, quase sempre abaixo da área mínima de mapeamento do sensor utilizado. Em relação a classe agricultura anual de pequena escala (62\%), a confusão se deu entre as classes outros (18\%), pasto sujo (12\%), área não observada (4\%) e vegetação secundária (4\%). A melhoria nos índices estatísticos da classificação, gerou uma medida de exatidão global de $78 \%$ e índice Kappa de 0,69.

Na Tabela 4 podemos observar a comparações da acurácia e dos erros de omissão e comissão entre as três técnicas de classificações. Podemos observar que todas as classes obtiveram acurácia maior quando classificadas com o KNN do que com o MAXVER e Bhattacharya. A classe vegetação secundária foi a classe que apresentou o mais alto índice de acerto (99\%) com o classificador $K N N$, erros de comissão de $8 \%$ e omissão de $1 \%$, enquanto as outras classificações apresentaram valores inferiores a 70\%. As classes pasto limpo e pasto sujo apresentaram maior exatidão quando classificadas com o classificador $K N N$. A classe pasto limpo atingiu a acurácia de $72 \%$, e pasto sujo obteve $94 \%$. Essa classe apresentou erros de comissão e omissão de $12 \%$ e $28 \%$, respectivamente, o que pode implicar em uma subestimativa das áreas de pasto sujo pelo KNN. Porém, esses valores são inferiores aos obtidos com o MAXVER (C=84\% e $\mathrm{O}=70 \%)$ e Bhattacharya $(\mathrm{C}=76 \%$ e $\mathrm{O}=42 \%)$. Para pasto sujo os erros foram de $28 \%$ de comissão e $6 \%$ de comissão (MAXVER $\mathrm{C}=78 \%$ e $\mathrm{O}=78 \%$ e Bhattacharya $\mathrm{C}=69 \%$ e $\mathrm{O}=64 \%)$. Os baixos índices de acurácia destas classes (pasto limpo e pasto sujo) obtidos pelo MAXVER e Bhattacharya se devem principalmente, a presença de gramíneas e arbustos, que podem apresentar intensidade de vigor vegetativo semelhantes, gerando confusões entre elas (JENSEN, 2011; PONZONI et al.,2012). 
Tabela 4: Acurácia (AC) e erros de comissão $(\mathrm{C})$ e omissão $(\mathrm{O})$ relativos às três classificações.

\begin{tabular}{lccccccccc}
\hline \multicolumn{1}{c}{$\%$} & \multicolumn{3}{c}{$\underline{M A X V E R}$} & \multicolumn{3}{c}{ Bhattacharya } & \multicolumn{3}{c}{$\underline{K N N}$} \\
Classe & AC & $\mathbf{C}$ & O & AC & $\mathbf{C}$ & O & AC & C & O \\
\hline Vegetação secundária & 66 & 35 & 34 & 69 & 33 & 31 & 99 & 8 & 1 \\
Pasto Limpo & 30 & 84 & 70 & 58 & 76 & 42 & 72 & 12 & 28 \\
Pasto sujo & 22 & 78 & 78 & 36 & 69 & 64 & 94 & 28 & 6 \\
Outros & 8 & 80 & 92 & 10 & 44 & 90 & 40 & 57 & 60 \\
Área urbana & 1 & 82 & 96 & 12 & 0 & 88 & 20 & 0 & 80 \\
Agricultura anual de & 8 & 73 & 92 & 4 & 85 & 96 & 62 & 0 & 38 \\
pequena escala & & & & & & & & & \\
Área não observada & 30 & 89 & 70 & 76 & 67 & 24 & 96 & 51 & 4 \\
Hidrografia & 3 & 50 & 97 & 17 & 17 & 83 & 99 & 0 & 3 \\
\hline
\end{tabular}

Observar-se na Tabela 4 que as classes outros e área urbana apresentaram baixa acurácia nos três classificadores. No entanto, a classificação com a abordagem $K N N$ foi a que apresentou melhor resultado, provavelmente pela inclusão dos atributos de forma e cor. A classe outros obteve $40 \%$ de acurácia (MAXVER $\mathrm{C}=8 \%$ e Bhattacharya $\mathrm{C}=10 \%)$ e a classe área urbana teve a acurácia estimada em $20 \%($ MAXVER $\mathrm{C}=1 \%$ e Bhattacharya $\mathrm{C}=12 \%$ ). Devido ao tamanho reduzido das áreas urbanas, com pequeno perímetro e a uniformidade da cor, é possível que os atributos forma e cor tenham melhorado a classificação destas áreas. O erro de omissão desta classe nas três abordagens de classificação foi maior que o erro de comissão para classe área urbana o erro de omissão com o classificador MAXVER foi de $96 \%$ (C=82\%), e Bhattacharya foi de $88 \%(\mathrm{C}=0 \%)$, e com $K N N$ o erro foi de $80 \%(\mathrm{C}=0 \%)$. Esses resultados mostram que todas as amostras classificadas como área urbana de fato pertenciam a essa classe, entretanto, grande parte das amostras de área urbana foram classificadas como pertencentes a outras classes. A baixa acurácia da área urbana pelos classificadores MAXVER e Bhattacharya está associada ao fato de que esta classe inclui áreas de comunidades, que são aglomerados populacionais, com uma estrutura urbana menos evidente, quando comparadas com os grandes centros urbanos. Esses aglomerados são manchas de menor tamanho, que se confundem com outros alvos como, por exemplo, bancos de areia e estradas, presentes na classe outros, e ou nas áreas de solo exposto presentes na classe pasto limpo. Quando foi incorporado o índice de forma e cor, o classificador $K N N$ conseguiu separar melhor os alvos do que os outros classificadores (KUX; PINHO, 2006; FLORENZANO,2011; JENSEN, 2011).

A classe agricultura anual de pequena escala apresentou baixa acurácia (Tabela 4) com os classificadores MAXVER (8\%) e Bhattacharya (4\%), enquanto que com o classificador $K N N$ obteve-se uma acurácia mais significativa, de $62 \%$. Os erros de comissão e omissão também foram significativamente mais altos nos resultados com o MAXVER $(\mathrm{C}=73 \%$ e $\mathrm{O}=92 \%)$ e Bhattacharya $(\mathrm{C}=85 \%$ e $\mathrm{O}=96 \%)$ do que com $K N N(\mathrm{C}=0 \%$ e $\mathrm{O}=38 \%)$. Essa melhoria deve-se principalmente ao acréscimo do atributo forma que identifica os talhões de agricultura, que apresentam formas geométricas, ajudando na identificação e distinção dessas áreas com as de outros usos e coberturas com níveis de cinza similares, mas que apresentam formas diferentes (YAN et al., 2006; FLORENZANO, 2011; GILBERTSON, et al., 2016; VOGELS et al., 2019).

Podemos observar na Tabela 4 que as classes área não observada e hidrografia alcançaram acurácia superior a $90 \%$ quando classificada com classificador $K N N$ do que com os outros classificadores. A classe área não observada obteve acurácia de 30\% com MAXVER e a76\% com Bhattacharya, enquanto que a classe hidrografia a acurácia foi de 3\% com MAXVER e 17\% com Bhattacharya (17\%). Consequentemente, os erros de comissão e omissão do classificador KNN também foram inferiores aos erros do MAXVER e Bhattacharya. Nota-se que para área não observada, o KNN apresentou $51 \%$ de erro de comissão e $4 \%$ de omissão (MAXVER C=89\% e O=70\% e Bhattacharya $\mathrm{C}=67 \%$ e $\mathrm{O}=24 \%$ ); já para a classe hidrografia o erro de comissão foi nulo e apenas $3 \%$ de erro de omissão foi obtido com o classificador KNN (MAXVER C=50\% e $O=97 \%$ e Bhattacharya $\mathrm{C}=17 \%$ e $\mathrm{O}=83 \%$ ), mostrando a importância do atributo de forma incluído na classificação deste alvo.

A Figura 7 é uma ampliação de um dos polígonos de Mosaico de Ocupação mapeados que ilustra as áreas mapeadas a partir das três técnicas empregadas nesse trabalho. Pode-se observar que, além da melhor discriminação dos alvos, outra vantagem da técnica $K N N$, em relação às outras duas técnicas testadas (MAXVER e Bhattacharya), é a sua capacidade de preservar a forma dos polígonos classificados. A Figura 7 mostra que as áreas de pasto limpo e de agricultura de anual de pequena escala apresentam formas 
geométricas bem definidas (Figura 7c), quando comparadas com as outras classificações (Figuras 7a e 7b), o que condiz com a realidade de campo. Nota-se também que, de uma forma geral, a classificação da Figura 7c apresenta menos ruídos do que as demais, principalmente em relação aos polígonos das classes pasto limpo e agricultura anual de pequena escala.

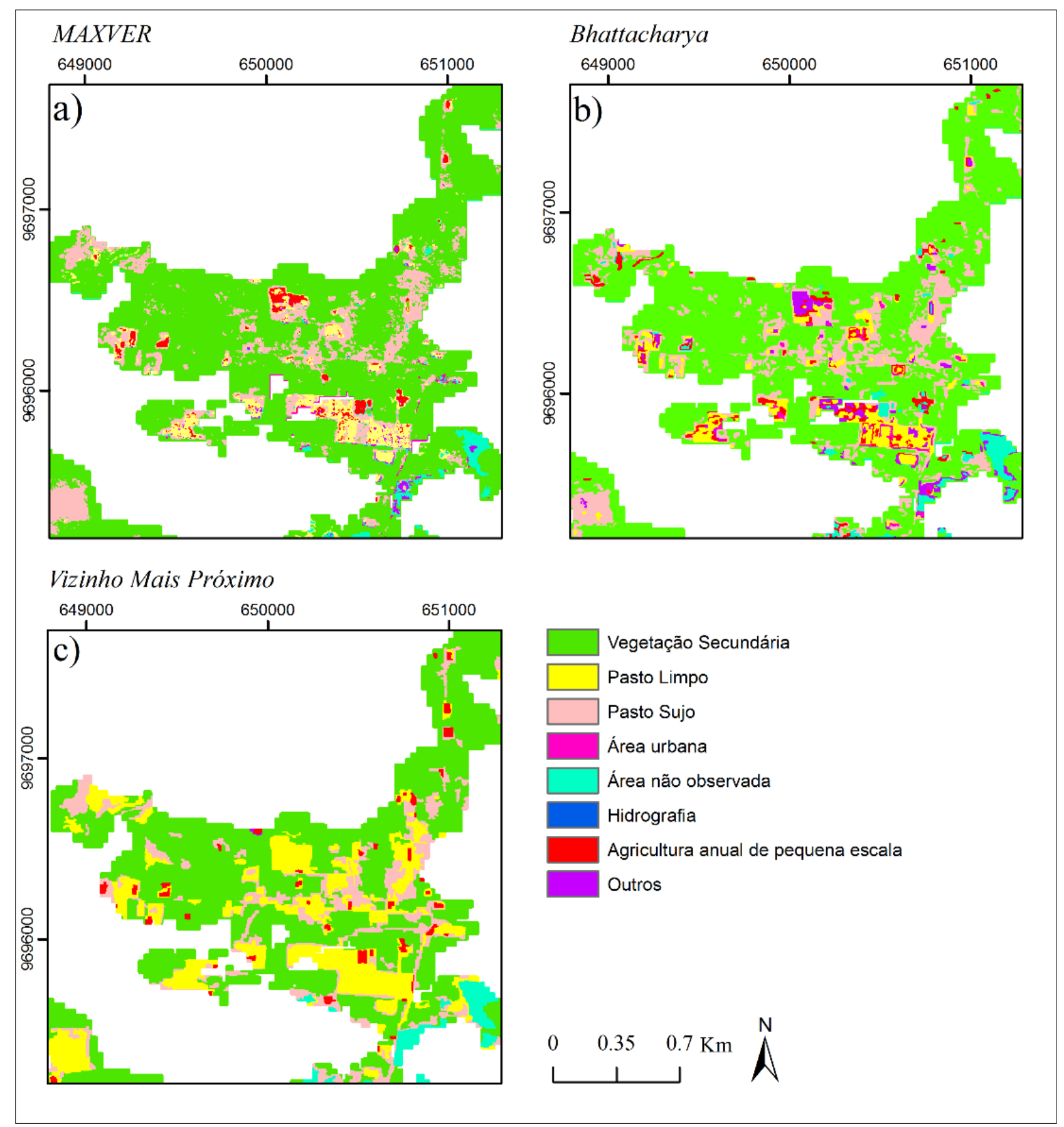

Figura 7: Detalhe da classificação a) MAXVER, b) Bhattacharya; c) Vizinho Mais Próximo*.

*As áreas em branco correspondem a outro tipo de classe que estão foram do polígono de mosaico de ocupação.

Embora a classificação derivada do algoritmo Vizinho Mais Próximo (atributos espectrais, estatísticos e de forma) e da segmentação multiresolução tenha apresentado um resultado superior, essa técnica apresenta aspectos operacionais que podem dificultar e aumentar o custo do mapeamento dessas áreas.

Essa abordagem exige um grande esforço de aprendizado na etapa inicial, que corresponde à preparação dos dados a serem utilizados, e a escolha apropriada de valores dos limiares para a segmentação e também para os atributos (tonalidade, cor, textura, forma, tamanho e etc.) na etapa de classificação. Então, para determinar os parâmetros de segmentação e classificação, além do conhecimento local das classes de uso e 
cobertura, é necessário realizar um estudo preliminar sobre os atributos que deseja utilizar, o que acaba resultando em maior consumo de tempo e na introdução de etapas de testes, além da necessidade do conhecimento prévio das classes de cobertura e de seus padrões espaciais. Portanto, para utilizar esses algoritmos é importante destinar uma boa parte do tempo para organização dos dados, assim como para definição dos parâmetros mais adequados para identificação e mapeamento dos alvos no processo de segmentação e classificação. Uma vez feito isso, é possível ampliar a classificação para outras cenas e identificar as áreas de agricultura anual de pequena escala na área de estudo.

\section{Considerações Finais}

Nesse trabalho foi demonstrado que, dos três algoritmos testados para o refinamento da classe Mosaico de Ocupação, o classificador K-Vizinho Mais Próximo foi o que apresentou maior exatidão global, maior acurácia das classes, e consequentemente, valores mais elevados de índice Kappa, demonstrando a importância da inclusão na segmentação e na classificação de parâmetros, que vão além dos espectrais. Dentre os parâmetros utilizados destaca-se o atributo de forma introduzido na etapa de classificação $(K N N)$, o qual possibilitou separar alvos com níveis de cinza semelhantes, mas que apresentam formas diferenciadas, podendo ser separados por métricas de forma. Além disso, nota-se uma maior eficiência da segmentação ao operar com mais atributos do que os espectrais como forma, cor, compacidade e suavidade, gerando segmentos mais homogêneos, com predominância de uma classe (alvo), minimizando assim, a inclusão de pixels que não se assemelham aos pixels do segmento. Outro ponto a ser destacado é o uso combinado desses atributos e classificador com a imagem de alta resolução espacial (5 metros) do sensor REIS/RepidEye-2.

Os altos valores de acurácia das classes e o índice Kappa (de cerca de 0,7) relativos aos resultados obtidos com o emprego do $K N N$, neste trabalho, mostram que é possível ampliar o refinamento da classe Mosaico de ocupação de maneira automática para outras regiões da Amazônia. Além disso, a metodologia desenvolvida neste trabalho pode ser adaptada e aplicada para a complementação de outras bases de dados existentes para a Amazônia, como a do MapBiomas e os dados do IBGE, que apresentam categorias agregadas, semelhantes às do Mosaico de Ocupação do TerraClass. Nesses mapeamentos, são destacadas categorias que representam os sistemas agrícolas e de pecuária que ocupam grandes áreas e tem uma produção voltada para o comércio em escala nacional e/ou internacional. Esses sistemas podem ser identificados e mapeados com maior facilidade, devido às grandes extensões de área ocupadas, utilizando produtos de baixa e/ou moderada resolução espacial. Entretanto, os resultados desse estudo mostram que é possível explicitar categorias agrícolas de produção em pequena escala, dando visibilidade às classes que têm sido frequentemente omitidas ou mal representadas nos mapeamentos de uso e cobertura da terra da Amazônia. Isso se dá, em parte, devido a questões operacionais, mas também devido ao desconhecimento sobre os sistemas produtivos de menor escala, que tem enorme importância na geração de alimentos e fornecimento de outros produtos, e na geração de renda para as populações locais e para as cidades e comunidades localizadas em seu entorno.

\section{Referências}

ALMEIDA, C. A. de; COUTINHO, A. C. ; ESQUERDO, J. C. D. M. ; DINIZ, C. G. ; ADAMI, M.; VENTURIERI, A.; DURIEUX, LDESSAY, .; N; GOMES, A. R. "High spatial resolution land use and land cover mapping of the Brazilian Legal Amazon in 2008 using Landsat-5 / TM and MODIS data," Acta Amaz., vol. 46, no. 3, pp. 291-302, 2016.

ANTUNES, M. A. H.; DEBIASI, P.; SIQUEIRA, J. C. D. S. Avaliação espectral e geométrica das imagens Rapideye e seu potencial para o mapeamento e monitoramento agrícola e ambiental. Revista Brasileira de Cartografia, v.66/1, p.105-113, $2014 . \quad$ Disponível <http://www.rbc.lsie.unb.br/index.php/rbc/article/view/789>. Acesso em: 13 mai.2015.

BAATZ, M.; SCHÄPE, A. Multiresolution segmentation: an optimization approach for high quality multiscale image segmentation. In: Angewandte geographische Informations verarbeitung. 2000.

BAStos, A. P. V., ORIANA ALMEIDA, CASTRO, E. R. de, MARIN, R. A., PIMENTEL, M. D S., RIVERO, S., ... BRUZEKE, F. J. (2010). Economia e Sociedade na Região do Tocantins, Pará. NAEA.

BENITEZ, F. L.; ANDERSON, L. O. ; FORMAGGIO, A. R. Evaluation of geostatistical techniques to estimate the spatial distribution of aboveground biomass in the Amazon rainforest using high-resolution remote sensing data.

Acta Amazonica, 46(2), 151 -160, 2016. 
CÂMARA, G.; SOUZA, R. C. M; FREITAS, U.M.; GARRIDO, J. "SPRING: Integrating remote sensingand GIS by object-oriented data modelling". Computers \& Graphics, 20: (3) 395-403, 1996.

CHALERMWAT, P. High performance automatic image registration for remote sensing. 1999. Tese (Doutorado) - George Mason University, Fairfax.

COHEN, J. A. Coefficient of Agreement for Nominal Scales. Educational and Psychological Measurement, v.20, n.1, p. 37-46, 1960.

CASTEJON, E. TerraPixel: an extensible image processing application prototype built using TerraLib classes and functions. Versão 1.0.4. [S. 1.], 18 jan. 2019. Disponível em: http://http://www.dpi.inpe.br/ castejon/wiki/doku.php?id=wiki:terrapixel.

COSTA, F. A. As múltiplas faces da Amazônia. FAPESP, Bélém, 2019.

COUTINHO, A.C; ALMEIDA, C. A.; VENTURIERI, A.; ESQUERDO, J. C.D. M.; SILVA, M. Uso e cobertura da terra nas áreas desflorestada da Amazônia Legal: TerraClass 2008. Brasília, DF: EMBRAPA; Belém: INPE,2013.

DAL'ASTA, A. P. Representações do fenômeno urbano na Amazônia contemporânea: observações no sudoeste Paraense. 2017. 207 p. IBI: <8JMKD3MGP3W34P/3MAQBFE>. (sid.inpe.br/mtcm21b/2016/08.23.18.20-TDI). Tese (Doutorado em Sensoriamento Remoto) - Instituto Nacional de Pesquisas Espaciais (INPE), São José dos Campos, 2016. Disponível em: <http://urlib.net/8JMKD3MGP3W34P/3MAQBFE>.

DURO, D.U.; FRANKLIN, S. E.; DUBÉ, M. G. "A comparison of pixel-based and object-based image analysis with selected machine learning algorithms for the classification of agricultural landscapes using SPOT-5 HRG imagery,” Remote Sens. Environ., vol. 118, pp. 259-272, 2012.

ESCADA, M. I. S. Evolução de padrões de uso e cobertura da terra na região Centro-Norte de Rondônia. 2003. 264 p. (INPE-10209-TDI/899). Tese (Doutorado em Sensoriamento Remoto) - Instituto Nacional de Pesquisas Espaciais (INPE), São José dos Campos, 2003. Disponível em: <http://urlib.net/6qtX3pFwXQZ3P8SECKy/yBuGo>. Acesso em: 15 ago. 2016.

FLORENZANO, T.G. Iniciação em sensoriamento remoto. São Paulo: Oficina de Texto, 2011.

GAMANYA, R.; DE MAEYER, P.; DE DAPPER, M. An automated satellite image classification design using object-oriented segmentation algorithms: A move towards standardization. Expert Systems with Applications, v. 32, n. 2, p. 616-624, 2007. ISSN 09574174.

GAVLAK, A. A. Padrões de mudança de cobertura da terra e dinâmica populacional no Distrito Florestal Sustentável da BR-163: população, espaço e ambiente. 2011. 177 p. (sid.inpe.br/mtc-m19/2011/08.02.16.24-TDI). Dissertação (Mestrado em Sensoriamento Remoto) - Instituto Nacional de Pesquisas Espaciais, São José dos Campos, 2011. Disponível em: <http://urlib.net/8JMKD3MGP7W/3A7C3ML>. Acesso em: 15 ago. 2016.

GILBERTSON, J. K.; KEMP, J.; VAN NIEKERK, A.Effect of pan-sharpening multi-temporal Landsat 8 imagery for crop type differentiation using different classification techniques Computers and Electronics in Agriculture., vol. 134, pp. 151-159, 2017.

GONZALEZ, R.C.; WOODS, R. E. Processamento de Imagens Digitais. Editora Edgard Blücher Ltda, 2000.

HUDSON, W. D.; RAMM, C. W. Correct formulation of the kappa coefficient of agreement. Photogrammetric Engineering \& Remote Sensing, Maryland, v.53, n.4, p.421-2, 1987.

INSTITUTO BRASILEIRO DE GEOGRAFIA E ESTATÍSTICA-IBGE. Monitoramento da cobertura e uso da terra do Brasil 2000-2010-2012-2014. Rio de Janeiro, 2017. Disponível em: https://biblioteca.ibge.gov.br/visualizacao/ livros/liv101469.pdf. Acesso em: 22 de março de 2018.

IBGE, Produção Agrícola Municipal 2014. Rio de Janeiro: IBGE, 2015.

IBGE, Produção da Pecuária Municipal 2014; Rio de Janeiro: IBGE, 2015.

JENSEN, J. R. Sensoriamento Remoto do Ambiente: Uma perspectiva em recursos terrestres. São José dos Campos: Parêntese, 2011.

KUX, H. J. H. ; PINHO, C. M. D. . Object-oriented analysis of high-resolution satellite images for intraurban land cover classification: case study in São José dos Campos, São Paulo state, Brazil. In: I 
International Conference on Object-based Image Analysis (OBIA2006), 2006, Salzburg, Austria. 1st International Conference on Object-based Image Analysis. Salzburg: Salzburg University, 2006. v. XXXVI.

LIMA, R. R.; TOURINHO, M. M. ; COS TA, J. P . C. da. Várzeas flúvio-marinhas da Amazônia Brasileira: Características e possibilidades agropecuárias. Belém: FCAP. Serviço de documentação e informação, 2001. $324 \mathrm{p}$.

MATHER, P. M. Computer Processing of remotely sensed images: An Introduction. $3^{\text {a }}$ edição, New York, John Wiley \& Sons. 1993. 352 p.

MELLO, D. G., COSTA, F. DE A.; JÚNIOR, S. B. Mercado e potencialidades dos produtos oriundos de floresta secundária em áreas de produção familiar. Novos Cadernos NAEA, 12, 137-148,2009.

MENESES, P. R.; ALMEIDA, T. De. Introdução Ao Processamento de Imagens de Sensoriamento Remoto 266, 2012.

MOLLAEI, Y. T.; KARAMSHAHI, A. A. Vegetation mapping through using satellite images of WorldView 2-A case study of Haft Barm, Shiraz. Journal of Wildlife and Biodiversity, v. 3, n. 1, p. 9-21, 2019.

MORARIU, O.; BURESCU, F. Agricultural land cover classification using Rapideye satellite imagery. Journal of Young Scientist, v. VI, 2018.

PLANET BLACKBRIDGE, Applications of the RapidEye Red Edge Band,2016.

PONZONI, F.J; SHIMABUKURO, Y. E; KUPLICH ,T.M. Sensoriamento Remoto da Vegetação. São José dos campos: Oficina de textos, $2012,2^{\circ} \mathrm{ed}$.

PROJETO MAPBIOMAS - Coleção 2.3 da Série Anual de Mapas de Cobertura e Uso de Solo do Brasil. Disponível em: http://mapbiomas.org/map\#coverage. Acesso em: 22 de março de 2018.

RICHARDS, J. A; JIA, X. Remote sensing digital image analysis: an introduction. 3th ed. Berlin; New York: Springer-Verlag, 2005. XXIV, 4-25p.

SCHUSTER, C.; FÖRSTER, M.; KLEINSCHMIT, B. Testing the red edge channel for improving land-use classifications based ; on high-resolution multi-spectral satellite data. International Journal of Remote Sensing, p. 5583-5599, 2012.

RAMOELO, A.; SKIDMOREB, A. K; CHOA, M. A; SCHLERFC, M.; MATHIEUA, R.; HEITKÖNIG, I.M.A. Regional estimation of savanna grass nitrogen using the red-edge band of the spaceborne rapideye sensor. International Journal of Applied Earth Observation and Geoinformation, v. 19, n. 1, p. 151$162,2012$.

SHANNON, C. E. Communication in the Presence of Noise. Proceedings of the IEEE, v.86, n. 2. 1998. 4447 a 457 pp.

SILVA, M. P. D. S.; CÂMARA, G.; ESCADA, M. I. S.; SOUZA, R. C. M. Remote sensing image mining: detecting agents of land-use change in tropical forest areas. International Journal of Remote Sensing, v. 29, p.4803-4822, 2008.

SOUZA, A. R. Economia e natureza: Padrões de uso e cobertura da terra associados a atividades agropecuárias e extrativistas de comunidades do sudoeste do Pará. 2017. 224 p. Dissertação (Mestrado em Sensoriamento Remoto) - Instituto Nacional de Pesquisas Espaciais (INPE), São José dos Campos, 2016. Disponível em: <http://urlib.net/8JMKD3MGP3W34P/3M8SD78>.

SOUZA, A. R. DE; ESCADA, M. I. S. ;MONTEIRO, A. M. V. Padrão da paisagem associado ao uso e cobertura da terra em comunidades ribeirinhas e de terra firme situadas no sudoeste do Pará. GEOGRAFIA. v.42, n. 2 mai/ago, 2017.

SCHUSTER, C.; FÖRSTER, M.; KLEINSCHMIT, B. Testing the red edge channel for improving land-use classifications based on high-resolution multi-spectral satellite data. International Journal of Remote Sensing, 33, 5583-5599, 2012.

STEHMAN, S. V. Estimating the kappa coefficient and its variance under stratified random sampling. Photogrammetric Engineering e Remote Sensing, 62(4):401-407, 1996. 
USTUNER, M. SANLI, F. B. AND DIXON, B. Application of Support Vector Machines for Land use Classification Using High-Resolution RapidEye Images: A Sensitivity Analysis. European Journal of Remote Sensing, 48, p.403-422, 2015.

VALERIANO, D. M.; ESCADA, M. I. S; CÂMARA, G.; AMARAL, S.; MAURANO, L.; RENNÂ, C. D.; ALMEIDA, C. A; MONTEIRO, A. M. V. Monitoramento do desmatamento. In: MARTINE, G. (ed.). População e sustentabilidade na era das mudanças ambientais globais: contribuição para uma agenda brasileira. Belo Horizonte: ABEP, 2012. p. 223-238.

VOGELS, M. F. A.; DE JONG, S. M.; STERK, G.; ADDINK, E. A. Mapping irrigated agriculture in complex landscapes using SPOT6 imagery and object-based image analysis - A case study in the Central Rift Valley, Ethiopia. International Journal of Applied Earth Observation and Geoinformation. vol. 75, no. May 2018, pp. 118-129, 2019.

YAN, G., MAS, J. F.;MAATHUIS, B. H. P.; XIANGMIN, Z.;VAN DIJK, P. M. Comparison of pixel-based and object-oriented image classification approaches-A case study in a coal fire area, Wuda, Inner Mongolia, China. International Journal of Remote Sensing, 27, 4039-4055, 2006. 